\title{
To the Question of the Reasons for Decrease in the Durability of Cutting Tools with a Diamond- Like Coating
}

\author{
Yacov Lieberman ${ }^{1}$, Svetlana Lukinskikh ${ }^{1, *}$, Ksenia Kulpina $^{1}$, and Yana Sarvarova ${ }^{1}$ \\ ${ }^{1}$ Ural Federal University, 620002, st. Lenin, 19 Yekaterinburg, Russia
}

\begin{abstract}
In this study, we investigate the reasons for the decrease in the durability of cutting tools with diamond-like carbon coating. We formulated a previously unexplored assumption that the destruction of the coating may occur due to the dissimilarity of the thermal expansion coefficients of the latter and the substrate material. To verify this assumption, we developed a special technique based on the theory of elasticity and carried out a study of several end mills and turning tools made of different materials. The results of our research confirm the validity of the hypothesis. We further propose methods of combating the discovered reason for the decrease in tool life.
\end{abstract}

\section{Introduction}

In recent years, the application of diamond-like carbon (DLC) coating has become a staple among methods of increasing durability of metal-cutting tools [1, 2]. According to most studies, DLC usually increases the tool life by $2-4$ times $[3,4,5]$. Considering the overall positive findings, data on the negative results of the use of DLCs tend to be viewed as either unreliable or as random outliers. However, the existence of such negative results is undeniable. An in-depth study of production practice and laboratory research established the following [6]:

1. For finishing turning and milling applications, DLC coating, as a rule, does increase the tool life by 2-4 times in the entire range of recommended cutting conditions [7].

2. In rough turning and milling applications, the opposite occurs: the wear rate of the coated tool exceeds the wear rate of uncoated tools by 3-4 times.

3. When drilling holes with a diameter of $4 \mathrm{~mm}$ or more, DLC increases the tool life similarly to finishing turning and milling; however, for diameters of up to $2.5-3 \mathrm{~mm}$, DLC sharply reduces the service life of drill bits and causes them to break.

4. In high speed turning, milling, or drilling applications, the tool life is almost the same with or without DLC coating.

The commonly known reasons for the above cases of unsatisfactory use of DLC, as determined by experiments and analysis of the physics of the cutting process, are as follows $[8,9$ and 10]:

\footnotetext{
*Corresponding author: swwl@mail.ru
} 
1. High brittleness of the coating, which manifests itself during roughing due to significant cutting forces that deform its substrate.

2. A significant increase in the surface roughness of the tool on which DLC is applied in the process of cathodic sputtering of graphite, which increases the coefficient of sliding friction in the "tool-workpiece" pair by $30-35 \%$.

3. Cutting temperatures exceeding $550-600^{\circ} \mathrm{C}$, this leads to a change in the structure of DLC coating.

Note, however, that this list is not exhaustive, as instances when the coating is still destroyed in the absence of the above factors have been also observed [11, 12]. We therefore hypothesized that there must be additional reasons for the decrease in tool life associated with using DLC. Specifically, our hypothesis is that the destruction of DLC coating may occur due to the difference in the coefficients of thermal expansion of the DLC coating and the substrate material. The greater this difference, the greater the tensile stress in the coating and at sufficiently high stresses the coating, so to speak, "breaks".

\section{Research methodology}

To test our assumption, we developed the following method based on the theory of elasticity.

1. Select the type of tool to be used in the test.

2. Create a solid model of the selected tool in SolidWorks.

3. Set the maximum allowable temperature for DLC tool cutting blades as the thermal load.

4. Set the area of application of the thermal load.

5. Use the SolidWorks Simulation system to analyze the deformations that occur in the created model under the influence of a given temperature.

6 . Based on the analysis, determine the relative elongation (deformation) of the section specified in step 4 under the influence of the temperature specified in step 3:

$$
\varepsilon=\Delta l / l_{0},
$$

where $l_{0}-$ is the initial length of the section; $\Delta l-$ is its absolute elongation.

7. Calculate the force "stretching" the area specified in step 4, under the influence of the temperature specified in step 3:

$$
F=\varepsilon \cdot E \cdot S,
$$

where $E$ - is the modulus of elasticity of the site material; $S$ - is the cross-sectional area of the latter.

8. Determine the stress $\sigma_{\text {DLC }}$ arising in the section of the DLC coating located in the same plane as the cross section of the working part area of the tool specified in step 6 :

$$
\sigma_{\mathrm{DLC}}=F / S_{\mathrm{DLC}},
$$

where $\sigma_{\mathrm{DLC}}-$ is the cross-sectional area of the DLC.

9. Compare $\sigma_{\mathrm{DLC}}$ with $\left[\sigma_{\mathrm{DLC}}\right]$ - tensile strength of DLC. 


\section{Analysis and findings}

We examined several DLC coated end mills and turning tools made of different materials (the characteristics of the materials are given in table 1) following the method described above.

Table 1. Characteristics of the materials of the investigated cutters and cutters

\begin{tabular}{|l|c|c|c|c|c|}
\hline \multicolumn{1}{|c|}{ Property } & P18 HSS & Steel 45 & T15K6 & DLC & Units \\
\hline Elasticity modules & $220 \cdot 10^{9}$ & $172 \cdot 10^{9}$ & $550 \cdot 10^{9}$ & $862 \cdot 10^{9}$ & $\mathrm{~N} / \mathrm{m}^{2}$ \\
\hline Tensile strength & $2,1 \cdot 10^{9}$ & $0,6 \cdot 10^{9}$ & $1,13 \cdot 10^{9}$ & $79 \cdot 10^{9}$ & $\mathrm{~N} / \mathrm{m}^{2}$ \\
\hline Mass Density & 8600 & 7698 & 11000 & 3510 & $\mathrm{~kg} / \mathrm{m}^{3}$ \\
\hline Thermal conductivity & 24,3 & 41 & 27 & 2100 & $\mathrm{~W} \cdot \mathrm{m}^{-1} \cdot \mathrm{K}^{-1}$ \\
\hline Specific Heat & 368 & 536 & 251 & 502 & $\mathrm{~J} /(\mathrm{kg} \cdot \mathrm{K})$ \\
\hline Coefficient of thermal expansion & $11 \cdot 10^{-6}$ & $12 \cdot 10^{-6}$ & $5,5 \cdot 10^{-6}$ & $1,3 \cdot 10^{-6}$ & $\mathrm{~K}^{-1}$ \\
\hline
\end{tabular}

\subsection{Examination of a cutter with a diameter of $5 \mathrm{~mm}$}

We first study a cutter with a diameter of $5 \mathrm{~mm}$ made of R18 steel, which is the most commonly used material for such tools. Assuming that the cutter is secured in the spindle of the machine with a chuck, and machines the surface with sections of side blades that are 2.5 $\mathrm{mm}$ long located at its end part, we set the temperature of this part to $500^{\circ} \mathrm{C}$, which is slightly below the maximum allowable for DLC and would not yet convert the coating into simple graphite. Using Solid Works Simulation, we will analyse the deformations that occur in the created model of the cutter under the influence of a given temperature (Figure 1).
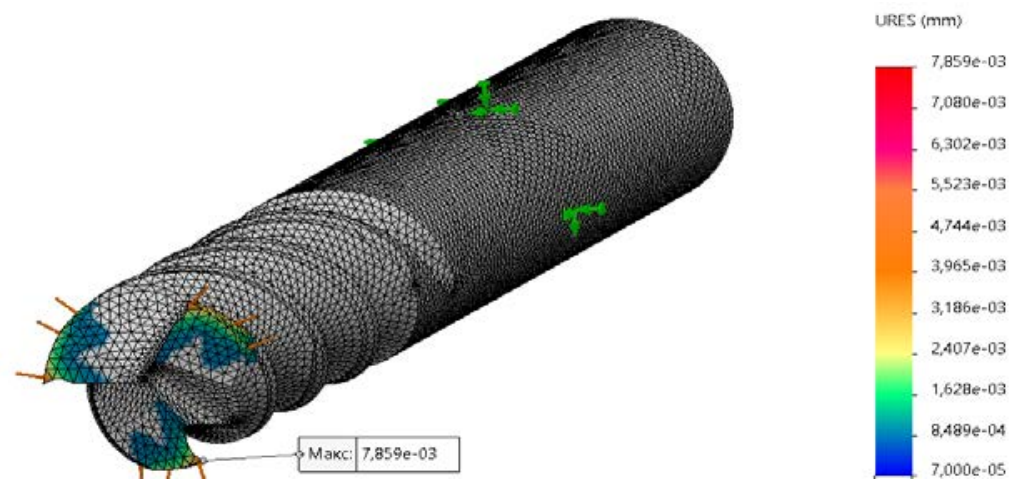

Fig. 1. Study of a $\emptyset 5 \mathrm{~mm}$ end mill made of P18 HSS

First, let us determine the value $\Delta l=7,859 \cdot 10^{-6} \mathrm{~m}$. Knowing it, we get:

$$
\varepsilon=\frac{\Delta l}{l_{0}}=\frac{7,859 \cdot 10^{-6}}{2,5 \cdot 10^{-3}}=0,0031436
$$

The cross-sectional area of the working part of the cutter body (Figure 2) is $S_{\mathrm{f}}=11,6 \cdot 10^{-6} \mathrm{~m}^{2}$, which allows us to calculate the deformation force:

$$
F=\varepsilon \cdot E \cdot S_{\mathrm{f}}=0,0031436 \cdot 220 \cdot 10^{9} \cdot 11,6 \cdot 10^{-6}=8022,46 \mathrm{~N}
$$


The cross-sectional area DLC $S_{\mathrm{DLC}}$ is determined by the cross-sectional perimeter of the cutter and the thickness of the coating, the latter usually being 5 microns. In this case, $S_{\mathrm{DLC}}=0,08 \cdot 10^{-6} \mathrm{~m}^{2}$ and, since the "tensile" force F acts on the DLC coating, the stress in it is

$$
\sigma_{\mathrm{DLC}}=\frac{F}{S_{\mathrm{DLC}}}=\frac{8022,46}{0,08 \cdot 10^{-6}}=100,28 \mathrm{GPa}
$$

However, the tensile strength DLC $\left[\sigma_{\mathrm{DLC}}\right]=79 \mathrm{Gpa}$, therefore the coating in this scenario will be inevitably destroyed.

Fig. 2. Cross-section of a cutter

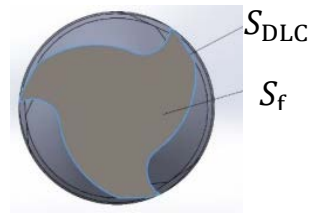

\subsection{Examination of a cutter with a diameter of $10 \mathrm{~mm}$}

Next we consider a cutter with a diameter of $10 \mathrm{~mm}$, also made of R18 steel. We will assume that it also works with the end part, with the temperature of the end part of the cutter of $500^{\circ} \mathrm{C}$, but with the length of the sections of the side blades $l_{0}=5 \mathrm{~mm}$. Based on the displacement analysis performed in SolidWorks Simulation, we establish that $\Delta l=11,59 \cdot 10^{-6} \mathrm{~m}$ and

$$
\varepsilon=\frac{\Delta l}{l_{0}}=\frac{11,59 \cdot 10^{-6}}{5 \cdot 10^{-3}}=0,002318
$$

The cross-sectional area of the working part of the cutter body in this case is $S_{\mathrm{f}}=46,39 \cdot 10^{-6} \mathrm{~m}^{2}$, which we use to find the deformation force:

$$
F=\varepsilon \cdot E \cdot S_{\mathrm{f}}=0,002318 \cdot 220 \cdot 10^{9} \cdot 46,39 \cdot 10^{-6}=23657,04 \mathrm{~N}
$$

Cross-sectional area of DLC $S_{\mathrm{DLC}}=0,15 \cdot 10^{-6} \mathrm{~m}^{2}$ and

$$
\sigma_{\text {DLC }}=\frac{F}{S_{\text {DLC }}}=\frac{23657,04}{0,15 \cdot 10^{-6}}=157,71 \mathrm{GPa}
$$

This stress is almost twice the tensile strength of the coating, and therefore the coating will be destroyed just like in the previous case.

\subsection{Examination of a lathe cutter}

While high-speed steel is commonly used as material for small diameter milling cutters, turning tools today are usually equipped with carbide inserts. Since it is advisable to use DLC in finishing applications, and finishing requires an increased rigidity of the cutting tool, which prevents vibration with a low frequency and significant amplitude, cutters with DLC coating are mainly made with brazed inserts. This is the type of a cutter we chose for this research.

Figure 3 shows a 3D model of the holder of the selected cutter and the geometric parameters of the plate soldered to it. Holder material is steel 45, inserts - T15K6. 

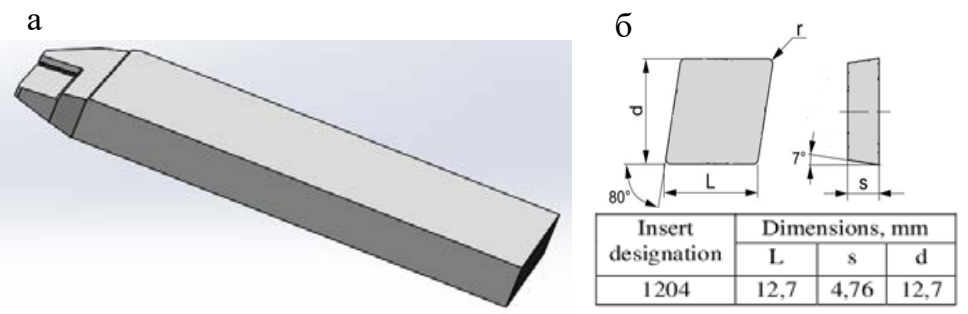

Fig. 3. Model of a cutter with a brazed plate: a - holder made of steel 45; b - plate geometrics

Figure 4 shows the displacement diagram obtained as a result of studying a carbide insert in SolidWorks Simulation at a given temperature load of $500^{\circ} \mathrm{C}$ in the cutting zone.

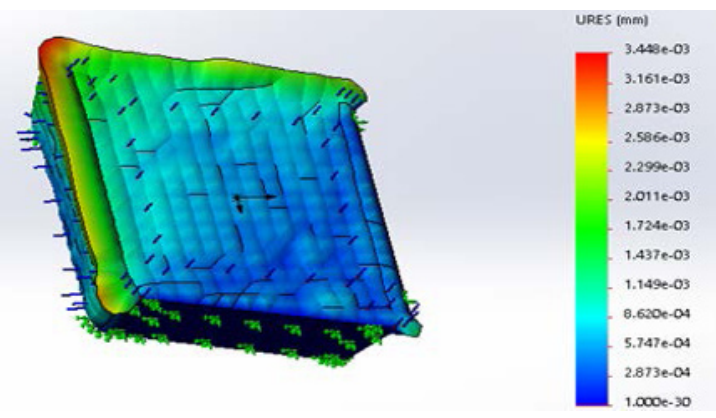

Fig. 4. Results of the study of displacements of a carbide insert in SolidWorks Simulation

Based on the analysis of displacements performed in SolidWorks Simulation, it was found that the absolute elongation of the plate is $\Delta l=3,448 \cdot 10^{-6} \mathrm{~m}$. With this elongation

$$
\varepsilon=\frac{\Delta l}{l_{0}}=\frac{3,448 \cdot 10^{-6}}{12,7 \cdot 10^{-3}}=0,000271496
$$

The value of $\mathrm{F}$ at such a relative elongation is:

$$
F=\varepsilon \cdot E \cdot S_{\mathrm{p}}=0,000271496 \cdot 550 \cdot 10^{9} \cdot 57,67 \cdot 10^{-6}=8611,45 \mathrm{~N},
$$

where $S_{\mathrm{p}}$ - is the cross-sectional area of the plate perpendicular to the direction of elongation. The cross-sectional area of the DLC applied to the front and main back surfaces of the plate is $S_{\mathrm{DLC}}=0,09 \cdot 10^{-6} \mathrm{~m}^{2}$. From here:

$$
\sigma_{\mathrm{DLC}}=\frac{F}{S_{\mathrm{DLC}}}=\frac{8611,45}{0,09 \cdot 10^{-6}}=95,68 \mathrm{GPa}
$$

Obviously, in this case, the tensile strength of DLC is again exceeded.

\section{Methods to combat the detected cause of tool life reduction}

The above analysis confirms our formulated hypothesis. However, it is possible to mitigate this newly discovered cause of DLC coating durability decrease. Let us consider further how this can be done. 


\subsection{Reducing the operating temperature of the coating}

One of the ways to eliminate the issue described above could be to reduce the operating temperature of the coating to significantly less than $500^{\circ} \mathrm{C}$.

For example, let us set the temperature of the cutting part of the tool shown in Figure 1 to $423^{\circ}$ C. Using Solid Works Simulation to perform analysis of deformations arising in the created model of the cutter under the influence of a given temperature, we obtain $\Delta l=0,9657 \cdot 10^{-6} \mathrm{~m}$ and

$$
\varepsilon=\frac{\Delta l}{l_{0}}=\frac{0,9657 \cdot 10^{-6}}{5 \cdot 10^{-3}}=0,00019314
$$

The value of $\mathrm{F}$ at such a relative elongation is

$$
F=\varepsilon \cdot E \cdot S_{\mathrm{f}}=0,00019314 \cdot 220 \cdot 10^{9} \cdot 46,39 \cdot 10^{-6}=1971,15 \mathrm{~N}
$$

And the tension in the coating is

$$
\sigma_{\mathrm{DLC}}=\frac{F}{S_{\mathrm{DLC}}}=\frac{1971,15}{0,15 \cdot 10^{-6}}=13,14 \mathrm{GPa}
$$

This is six times less than the tensile strength of DLC coating, which means that the coating will not collapse. There are various ways to reduce the temperature of the coating, for example, by reducing the cutting speed when using it. However, this would result in decreased processing productivity, so the total economic effect of increasing tool life may be insignificant. Therefore, we should consider other solutions.

\subsection{Using high-strength invar alloys as a substrate}

In [13], we proposed, in particular, to use high-strength Invar alloys with a coefficient of thermal expansion close to the coefficient of thermal expansion of DLC as a substrate for DLC instead of high-speed steel or carbide plates. An example of an alloy suitable for this purpose is the high-strength Invar alloy described in [14], the characteristics of which are given in Table 2 .

In terms of its properties, this alloy is comparable to other popular modern instrument materials, and could well become one of them. Below we demonstrate that the use of such an alloy is, in fact, effective to prevent destruction of DLC coating.

We start with creating a model of an end mill with a diameter of $10 \mathrm{~mm}$ and examine it under the same conditions as a similar mill made of P18 steel (with the temperature of the blades of the cutting part set at $500^{\circ}$ C). Using SolidWorks Simulation, we get $\Delta l=1,298 \cdot 10^{-6} m$ and

$$
\varepsilon=\frac{\Delta l}{l_{0}}=\frac{1,298 \cdot 10^{-6}}{5 \cdot 10^{-3}}=0,0002596
$$

According to the obtained value of $\varepsilon$, the data in Table 2 and the size of the cutter, we find:

$$
F=\varepsilon \cdot E \cdot S_{\mathrm{f}}=0,0002596 \cdot 220 \cdot 10^{9} \cdot 46,39 \cdot 10^{-6}=2408,57 \mathrm{~N}
$$

From here: 


$$
\sigma_{\mathrm{DLC}}=\frac{F}{S_{\mathrm{DLC}}}=\frac{1971,15}{0,15 \cdot 10^{-6}}=16,057 \mathrm{GPa}
$$

While this result is not as good as in the previous case, this is still almost five times less $\left[\sigma_{\mathrm{DLC}}\right]$. Consequently, no destruction of DLC will occur in a cutter made of the invar alloy.

Table 2. Characteristics of the Invar alloy according to the patent of the Russian Federation No. 2023739

\begin{tabular}{|c|c|c|}
\hline Property & The investigated invar alloy & Units \\
\hline Elasticity modules & $200 \cdot 10^{9}$ & $\mathrm{~N} / \mathrm{m}^{2}$ \\
\hline Tensile strength & $1,8 \cdot 10^{9}$ & $\mathrm{~N} / \mathrm{m}^{2}$ \\
\hline Mass Density & 8000 & $\mathrm{~kg} / \mathrm{m}^{3}$ \\
\hline Thermal conductivity & 13 & $\mathrm{~W} \cdot \mathrm{m}^{-1} \cdot \mathrm{K}^{-1}$ \\
\hline Specific Heat & 460 & $\mathrm{~J} /(\mathrm{kg} \cdot \mathrm{K})$ \\
\hline Coefficient of thermal expansion & $1,5 \cdot 10^{-6}$ & $\mathrm{~K}^{-1}$ \\
\hline
\end{tabular}

Now let us consider a lathe cutter similar to the one studied earlier, but with a head made of Invar alloy. We select a section of the same dimensions as on the carbide plate shown in Fig. 4. At a cutting temperature of $500^{\circ} \mathrm{C}$, the absolute elongation of this section will be equal to $\Delta l=2,334 \cdot 10^{-6} \mathrm{~m}$. With this elongation:

$$
\varepsilon=\frac{\Delta l}{l_{0}}=\frac{2,334 \cdot 10^{-6}}{12,7 \cdot 10^{-3}}=0,0001837795
$$

With this elongation

$$
F=\varepsilon \cdot E \cdot S_{\mathrm{p}}=0,0001837795 \cdot 200 \cdot 10^{9} \cdot 57,67 \cdot 10^{-6}=2119,71 \mathrm{~N}
$$

Therefore:

$$
\sigma_{\mathrm{DLC}}=\frac{F}{S_{\mathrm{DLC}}}=\frac{2119,71}{0,09 \cdot 10^{-6}}=23,55 \mathrm{GPa}
$$

This stress is significantly less than the tensile strength of the DLC, which indicates that the coating will not fail.

The advantages of using a high-strength Invar alloy for other metal-cutting tools are also confirmed by further studies. However, it should be noted that such an alloy is more expensive than traditional instrumental materials. Therefore, using it for the entire tool would not be practical. For mill and drills, for example, it makes more sense to weld the working part of the tool to its fastening part. Turning cutters can be made modular, with a replaceable head manufactured from Invar alloy. An example of such a cutter, similar to that proposed in [15], is shown in Fig. 5.

\section{Conclusion}

Based on the analysis performed in this study, it can be argued that the dissimilarity of the thermal expansion coefficients of DLC and the substrate material is one of the reasons for the destruction of DLC coating. The performed research allowed us to identify several methods that, in a number of cases, will prevent the destruction of DLC coating. In particular, we suggest reducing the operating temperature of the coating or using high- 
strength Invar alloys as a substrate. To reduce the cost of the tools when using the more expensive Invar alloys, we propose several constructive solutions for prefabricated cutters.

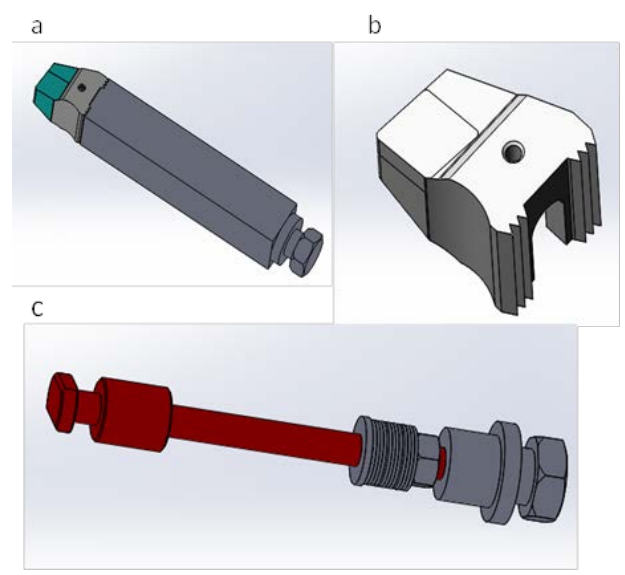

Fig. 5. Continuous cutter with replaceable module made of high-strength Invar alloy with diamondlike coating: a - complete cutter; b - replaceable cutting module made of Invar alloy with a dedicated area equal to the dimensions of the plate; $\mathrm{c}$ - the clamping mechanism of the cutter

\section{References}

1. Yu.V. Polyanskov, V.P. Tabakov, A.P. Tamarov Technological methods of increasing the wear resistance of cutting tools and machine parts (UISU, Ulyanovsk, 1999)

2. Increasing the cutting ability of the tool. Electronic resource, URL: https://inreko.ru/poleznaya-informaciya/detail.php?ID $=24$

3. I.Sh. Trakhtenberg, S.A. Plotnikov, Ya.L. Liberman, V.A. Kanalina, A.V. Vladimirov Service properties of cutting tools hardened with diamond-like coating. Diamond and Related Materials v2, pp.1434-1438 (1993).

4. M. Dai, K. Zhou, Z. Yuan et al. The cutting performance of diamond and DLC-coated cutting tools Diamond and Related Materials, v. 9 (9-10), pp. 1753-1757 (2000).

5. Diamond-like coatings. Properties of diamond and graphite,el., URL: https://xn--80aaafltebbc3auk2aepkhr3ewjpa.xn--p1ai/almazopodobnyie-pokryitiya/

6. Ya.L. Lieberman, V.A. Shterenzon. The phenomenon of a decrease in the durability of a cutting tool when applying a hard diamond-like coating, International scientific journal "Symbol of science" v. 5, pp.64-67 (2015)

7. A.S. Vasilyeva, A.A. Kutina et al., Handbook of a mechanical engineer (Innovative mechanical engineering. Moscow, 2018).

8. Ya.L. Lieberman, V.A. Kanalina. Cutting forces for machining tools with diamond-flated coating Mechanical Engineering Bulletin, v.5, p. 62 (1998).

9. H. Liu, A. Tanaka, K. Umeda, Thin Solid Films, v. 28, pp.162-168 (1999).

10. J. Veverkova, S. Hainworth, Wear, v. 264, pp. 518-525 (2008).

11. A.V. Varlashkin, S.I. Krasnosvobodtsev et al. Deposition of smooth HTSC films with a solid-state YAG, Journal of Technical Physics v. 77(5), pp.127-129 (2007).

12. A.A. Chizik, A.S. Mikhailov, Method and device for surface modification, Patent 2470407 (2012)

13. Ya.L. Lieberman K.A. Kulpina, Ya.E. Sarvarova, Patent appl. 2019141841 (2019)

14. V.M. Kardonskiy, High-strength invar alloy, Patent 2023739 (1994)

15. Ya.L. Lieberman, S.S. Kugaevsky, Cutting module, Patent 187730 (2019) 